\section{Check for updates}

Cite this: Inorg. Chem. Front., 2020, 7, 4600

Received 2nd September 2020,

Accepted 5th October 2020

DOI: 10.1039/d0qi01067g

rsc.li/frontiers-inorganic

\title{
A computational study of the reactivity of rare-earth/phosphorus Lewis pairs toward polymerization of conjugated polar alkenes $\uparrow$
}

\author{
Yanan Zhao, (D) a Gen Luo, (DD ${ }^{a, b}$ Xin Xu, (D) ${ }^{c}$ Zhaomin Hou (D) ${ }^{\text {a,d }}$ and Yi Luo (D) *a
}

The polymerization mechanism of methyl methacrylate (MMA) catalyzed by rare-earth/phosphorus (RE/P) Lewis pairs has been systematically studied through density functional theory (DFT) calculations. Having achieved an agreement between theory and experiment, it is found that the polymerization of MMA mediated by intermolecular RE/P Lewis pairs mainly follows the bimetallic mechanism, while the monometallic pathway could not be excluded in the case of a La analogue. In comparison with phenyl phosphorus as a Lewis base, the higher activity of cyclohexyl phosphorus toward MMA polymerization could be ascribed to the electron-donation ability, rendering more electron flow in the addition reaction. Besides, a computational modelling of analogous intramolecular RE/P systems indicates that the size of the central metal and the length of the chain connecting Lewis pairs play an important role in the catalytic activity.

\section{Introduction}

Polymers derived from conjugated polar monomers have attracted much attention because an unsaturated bond and a polar functional group remain in the polymer chain and thus are capable of meeting specific applications or undergoing further functionalization. Besides the radical and anionic polymerization methods, ${ }^{1,2}$ the catalytic coordination insertion $^{3}$ and conjugate addition such as group-transfer polymerization $(\mathrm{GTP})^{4}$ and Lewis pair polymerization $(\mathrm{LPP})^{5}$ are also useful for the synthesis of such polymers. The former is usually problematic in controllability, and transition-metal catalyzed coordination insertion is known to suffer from poisoning by the functional group. ${ }^{3}$ In the context of conjugate

\footnotetext{
${ }^{a}$ State Key Laboratory of Fine Chemicals, School of Chemical Engineering, Dalian University of Technology, Dalian 116024, China.E-mail: luoyi@dlut.edu.cn ${ }^{b}$ Institutes of Physical Science and Information Technology, Anhui University, Hefei 230601, China

${ }^{{ }^{C} K e y ~ L a b o r a t o r y ~ o f ~ O r g a n i c ~ S y n t h e s i s ~ o f ~ J i a n g s u ~ P r o v i n c e, ~ C o l l e g e ~ o f ~ C h e m i s t r y, ~}$ Chemical Engineering and Materials Science, Soochow University, Suzhou 215123, China

${ }^{d}$ Organometallic Chemistry Laboratory, RIKEN Cluster for Pioneering Research, and Advanced Catalysis Research Group, RIKEN Center for Sustainable Resource Science, 2-1 Hirosawa, Wako, Saitama 351-0198, Japan

$\dagger$ Electronic supplementary information (ESI) available: Computational details, figures showing the monometallic pathway and geometrical parameters of key stationary points, and optimized Cartesian coordinates of all stationary points together with their single-point energies (a.u.) in solution and the imaginary frequencies $\left(\mathrm{cm}^{-1}\right)$ of transition states (XYZ file). See DOI: 10.1039/d0qi01067g
}

addition polymerization, LPP has attracted recent interest, thanks to the cooperation between the Lewis acid and base in chain initiation, propagation, and termination. In view of the cooperative behavior in LPP, the polymerization activity could be regulated by both the Lewis acid and Lewis base and thus showed rich chemistry, as demonstrated by previous works. ${ }^{6}$ Since the first LPP work reported by Chen and coworkers in $2010,{ }^{5 a}$ significant progress has been made in this field. ${ }^{5-h}$ In Chen's primary work, $\mathrm{Al}\left(\mathrm{C}_{6} \mathrm{~F}_{5}\right)_{3}$-based Lewis pairs were demonstrated to catalyze the polymerization of conjugated polar alkenes and a high molecular weight polymerization product was obtained. Hong ${ }^{7}$ and Zhang ${ }^{6,8}$ reported a series of maingroup FLP catalysts for the polymerization of a wide range of conjugated polar monomers, some of which showed living and controllable features. In spite of group 4 metal involved ionpair polymerization, ${ }^{9}$ transition-metal containing LPP is not well established. ${ }^{10,11}$ Therefore, a highly active transition-metal containing LPP system is still a worthy challenge, which could be improved by modulation of Lewis acids and bases.

It is known that rare-earth metal complexes were reported to not only mediate the synthesis of small molecules ${ }^{12,13 b}$ but also catalyze the polymerizations of non-polar or polar olefins. ${ }^{13}$ To regulate the acidity of Lewis acids in LPP, Xu et al. developed intramolecular and intermolecular rare-earth/phosphorus (RE/P) Lewis pairs (Chart 1) for polymerizing conjugated polar monomers such as methyl methacrylate (MMA). ${ }^{14}$ Their works demonstrated that the polymerization activity is significantly affected by rare-earth metals and Lewis bases. The authors observed that La complex 3 showed higher activity 


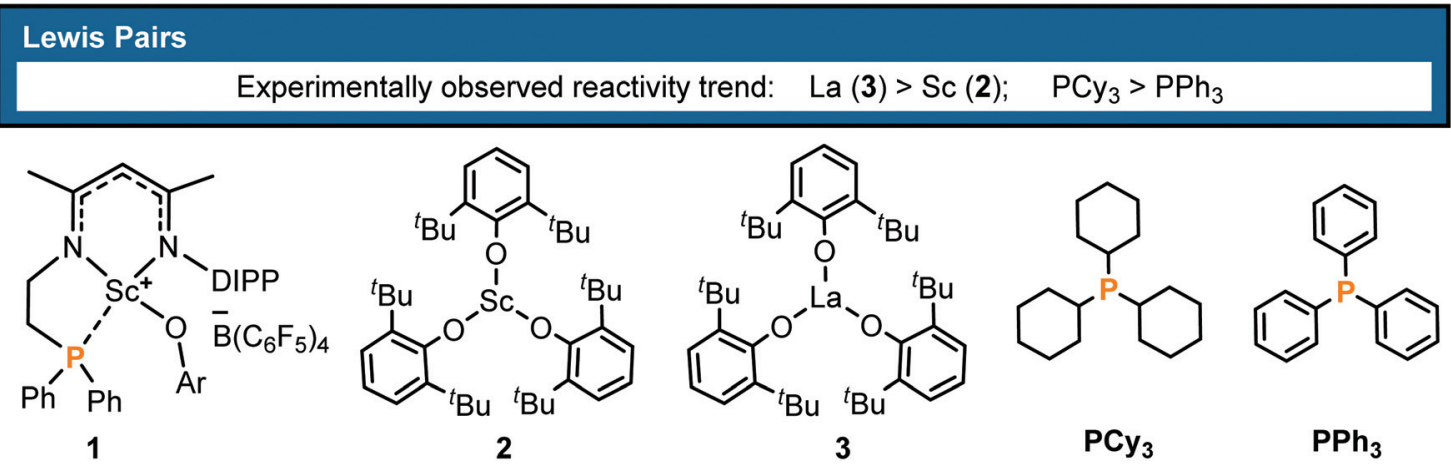

Chart 1 Rare-earth metal Lewis pairs reported for LPP. ${ }^{14}$

than Sc analogue 2 and Lewis base $\mathrm{PCy}_{3}$ exhibited higher activity compared with $\mathrm{PPh}_{3}$. However, the origin of such activity discrepancy remained unclear.

A few theoretical mechanistic works on the mechanism of MMA polymerization by main-group FLPs have been documented. ${ }^{15-17}$ Chen and Cavallo at el. reported the calculations on the formation of the zwitterionic active species in LPP of MMA and found that NHC-based zwitterions were more stable compared with $\mathrm{PR}_{3}$-based analogues and the MMA addition favorably followed the bimetallic pathway. ${ }^{15}$ They also conducted mechanistic studies on the chain propagation and termination of LPP of conjugated polar monomers catalyzed by Al-based FLPs and found that intramolecular backbiting cyclization might account for the chain-termination, ${ }^{16}$ being in line with separate works by Lu et al. ${ }^{18}$ Taton and coworkers computationally demonstrated a cooperative mechanism in MMA polymerization catalyzed by a $\mathrm{PR}_{3} / \mathrm{Me}_{3} \mathrm{SiNTf}_{2}$ Lewis pair. ${ }^{17}$ In spite of these mechanistic studies on the main-group LPP, the theoretical study of such 1,4-conjugate addition polymerization catalyzed by $\mathrm{RE} / \mathrm{P}$ Lewis pairs, to the best our knowledge, has not been reported to date.

Stimulated by our previous theoretical works on rare-earth metal catalyzed polymerizations, ${ }^{19}$ we are interested in the molecular-level factors governing the polymerization activity observed in the RE/P systems, with the purpose of elucidating the related reaction mechanism. It is generally considered that, in the LPP, stronger acidity of the Lewis acid could induce higher activity. Our primary calculation based on the HSAB (hard and soft acids bases) principle and DFT indicates that 2 has higher chemical hardness and thus stronger Lewis acidity in comparison with 3 (0.20 vs. $0.16 \mathrm{eV}) .{ }^{19 c, 20}$ However, as aforementioned, the activity of 3 is higher than that of $2,{ }^{14 b}$ which drove us to explore the origin of such activity discrepancy. In the present work, DFT calculations have been conducted for the intramolecular and intermolecular RE/P Lewis pairs (Chart 1) toward the polymerization of MMA, which is a commercially important and scientifically interesting commodity acrylic monomer. On the basis of the clarification of the related polymerization mechanism, the origin of different activity between Sc and $\mathrm{La}$ analogues and the effects of different Lewis bases have been elucidated, which could provide a piece of information for the development of LPP systems.

\section{Results and discussion}

\section{Polymerization mechanism}

It is generally considered that FLP (frustrated Lewis pair) mediated polymerization of conjugated polar alkenes follows Michael addition to grow a polymer chain rather than coordination insertion or single electron transfer. ${ }^{15,16}$ In the case of intramolecular Lewis pairs such as $\mathbf{1}^{+}$(Chart 1 ), as shown in Fig. 1, the reaction starts with the coordination of monomer MMA and then 1,4-addition $\left(\mathbf{1 a}_{\text {coor }} \rightarrow \mathbf{1} \mathbf{a}_{\mathrm{TS}} \rightarrow \mathbf{1 a}\right)$ could occur to provide $1 \mathrm{a}$ with a newly formed $\mathrm{P}-\mathrm{C}$ bond. While the incoming monomer approaches the metal center of the active species 1a, the 1,4-addition reaction repeatedly takes place to form C$\mathrm{C}$ bonds and the polymerization could smoothly occur. Such a C-C formation process has a moderate energy barrier (19.6 kcal mol $\mathrm{m}^{-1}$ ) and is exergonic (Fig. 1), suggesting a feasible polymerization event.

In the case of the intermolecular RE/P Lewis pair (Chart 1), the monometallic and bimetallic mechanisms have been considered, respectively. As shown in Fig. 2, starting with $\mathbf{2 C}$, the energy barrier for the monometallic mechanism $\left(\mathbf{2 T S}_{\mathbf{d e}}\right.$, $34.9 \mathrm{kcal} \mathrm{mol}^{-1}$, see Fig. S2 in the ESI† for the complete monometallic pathway) is significantly higher than that for the bimetallic pathway $\left(2 \mathbf{T S}_{\mathrm{DE}}, 20.2 \mathrm{kcal} \mathrm{mol}^{-1}\right.$ ), showing a preference for the bimetallic reaction manner. Although the enchainment of the second MMA is slightly endergonic (conversion of $\mathbf{2 C}$ to $\mathbf{2 F}$ ), the addition of the third MMA is exergonic (2F to $\mathbf{2 H}$ ), suggesting an energetically favorable enchainment process.

To obtain better understanding of the priority of the bimetallic mechanism, the distortion/interaction analyse ${ }^{21}$ have been comparatively performed for the key transition states

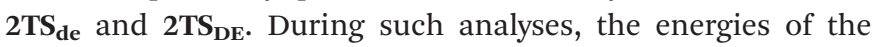
monomer moiety and the remaining metal complex (two fragments) in the TS geometries were evaluated via single-point calculations. Such single-point energies of the fragments and the energy of the TS were used to estimate the interaction 


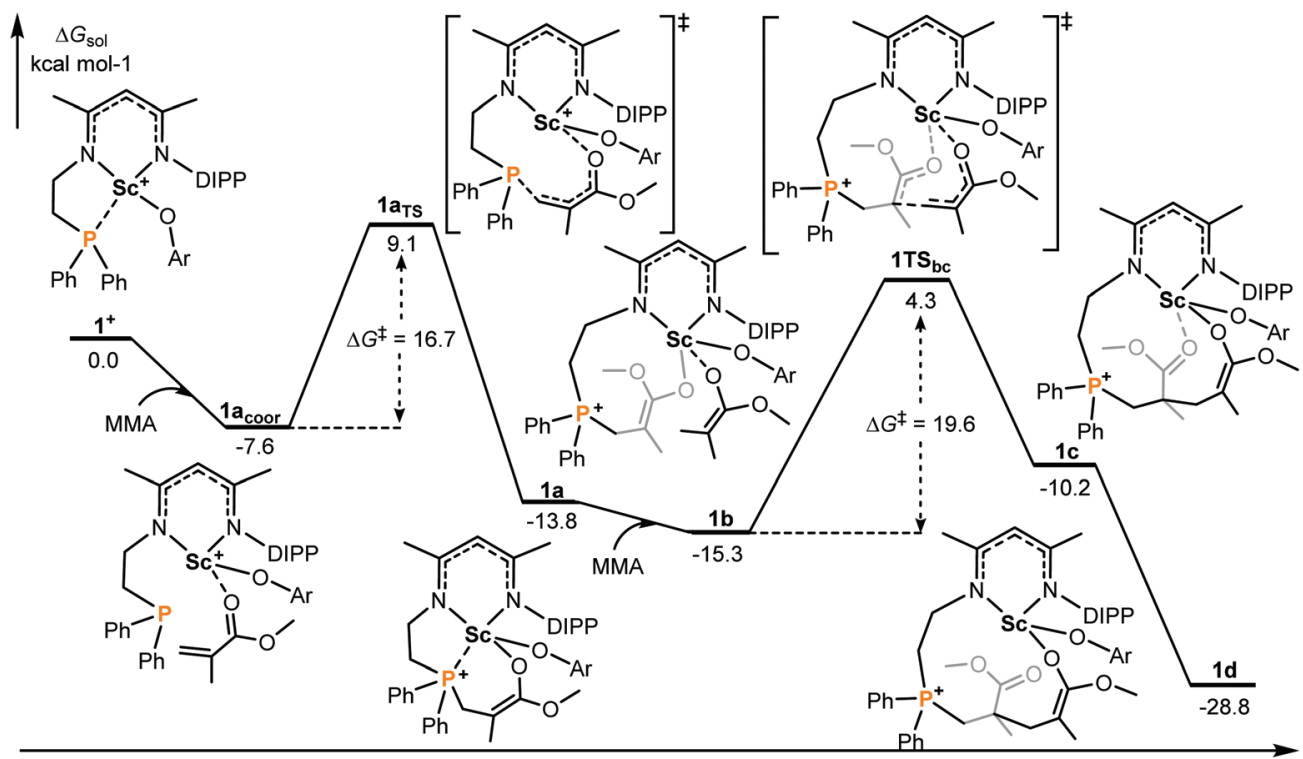

Fig. 1 Computed energy profiles (M06(SMD)/6-311G** $\cap S D D / / B 3 P W 91 / 6-31 G * \cap S D D)$, see the ESI $\dagger$ for more details for $1^{+}$mediated polymerization of MMA (intramolecular RE/P systems). Free energies ( $\mathrm{kcal} \mathrm{mol}^{-1}$ ) are relative to isolated reactants.

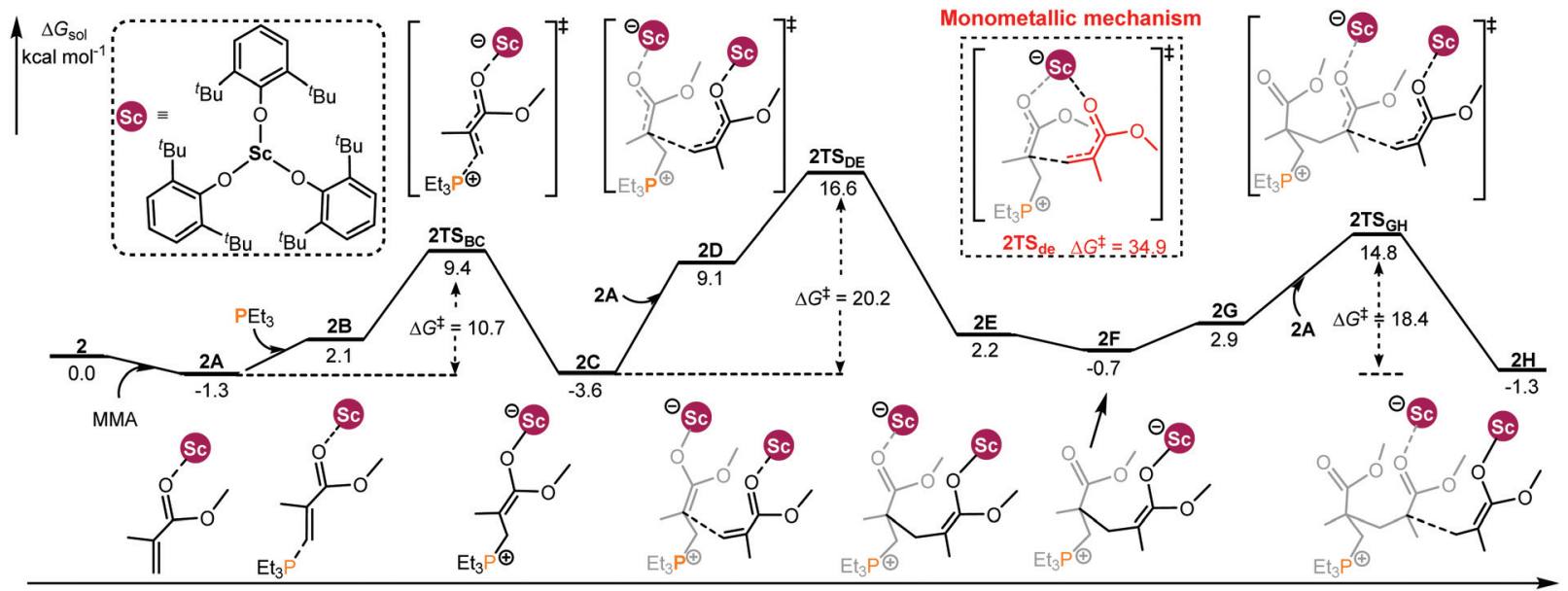

Fig. 2 Computed energy profiles for 2/PEt 3 mediated (intermolecular RE/P systems) bimetallic enchainment of MMA. Free energies (kcal mol ${ }^{-1}$ ) are relative to isolated reactants.

energy $\Delta E_{\text {int }}$. These energies, together with the energies of the respective fragments in their optimal geometry, allow for the estimation of the deformation energies of the two fragments, $\Delta E_{\text {def }}$ (cat.) and $\Delta E_{\text {def }}$ (mono.). As the energy of the TS, $\Delta E_{\mathrm{TS}}$, is evaluated with respect to the energy of the two separated fragments, the relation $\Delta E_{\mathrm{TS}}=\Delta E_{\mathrm{int}}+\Delta E_{\text {def }}$ (cat.) $+\Delta E_{\text {def }}$ (mono.) holds. As shown in Fig. 3, the total deformation energy $\Delta E_{\text {def }}$ in 2 TS $_{\mathrm{de}}$ is $60.7(12.8+47.9) \mathrm{kcal} \mathrm{mol}^{-1}$, which could be hardly balanced out by its $\Delta E_{\text {int }}\left(-12.3 \mathrm{kcal} \mathrm{mol}^{-1}\right)$, leading to high $\Delta E_{\mathrm{TS}}$ of $48.4 \mathrm{kcal} \mathrm{mol}^{-1}$. However, the $\Delta E_{\mathrm{def}}$ in $2 \mathbf{T S}_{\mathrm{DE}}(31.9 \mathrm{kcal}$ $\mathrm{mol}^{-1}$ ) is compensated by an interaction energy of $-9.2 \mathrm{kcal}$ $\mathrm{mol}^{-1}$, leading to $\Delta E_{\mathrm{TS}}=22.7 \mathrm{kcal} \mathrm{mol}^{-1}$, which is lower than that for $2 \mathbf{T S}_{\mathbf{d e}}$. As a consequence, the less steric hindrance inducing smaller deformations of the metal complexes could account for the higher stability of $\mathbf{2} \mathbf{T S}_{\mathbf{D E}}$. A comparison of the structures of the two transition states indicates that the $\mathrm{C} 1-\mathrm{C} 2$ distance in $2 \mathbf{T S}_{\mathbf{d e}}$ is obviously shorter than that in $2 \mathbf{T S}_{\mathbf{D E}}$ (2.09 vs. $2.17 \AA$ A Fig. 3), suggesting a more crowded environment at the reaction center in $\mathbf{2} \mathbf{T S}$ de. This is also consistent with the greater deformations in the $\mathbf{2 T S}_{\mathrm{de}}$ case.

\section{Metal effect on catalyst activity}

It was reported that different metal centers led to a significant activity difference in the intermolecular FLP system. ${ }^{14 b}$ This drove us to computationally compare the MMA addition mediated by an analogous complex such as 3 (La complex) with the same ligand as that in 2 (Sc complex, Chart 1). Like the $2 / \mathrm{PEt}_{3}$ system, it is also found that, in the case of $3 / \mathrm{PEt}_{3}$, 

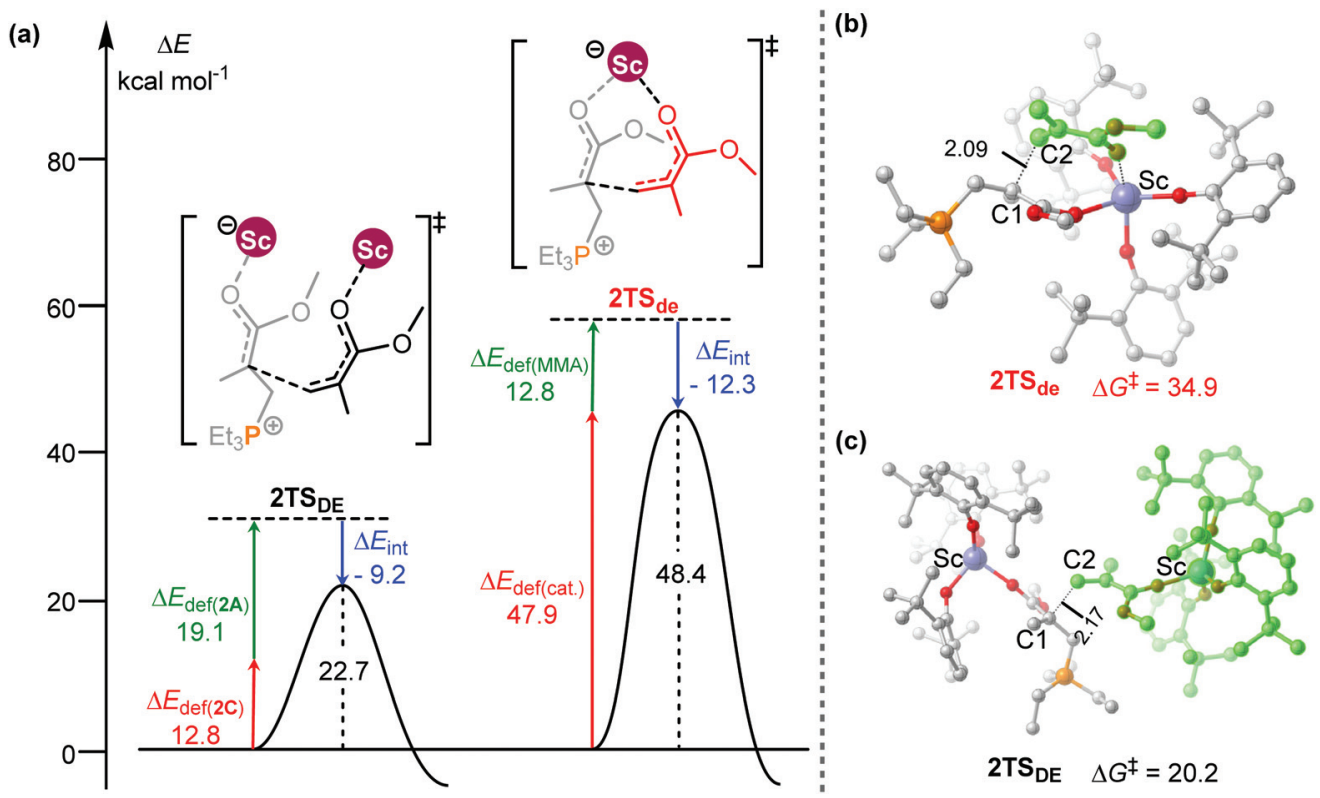

Fig. 3 (a) Distortion/interaction analyses $\left(\mathrm{kcal} \mathrm{mol}^{-1}\right.$ ) and geometric parameters (distances in $\AA$ ) of (b) $2 \mathrm{TS}_{\mathrm{de}}$ and (c) $2 \mathrm{TS}_{\mathrm{DE}}$.

the bimetallic mechanism is both kinetically and thermodynamically more favorable than the monometallic pathway (Fig. 4 and $\mathrm{S} 3 \dagger$ ). However, the overall energy barrier of the monometallic pathway is $16.1 \mathrm{kcal} \mathrm{mol}^{-1}$, which is not totally insurmountable under experimental conditions (room temperature). Besides, the monometal-mediated insertion process of MMA tends to be exergonic in chain propagation ( $\mathbf{3} \mathbf{f} \rightarrow \mathbf{3} \mathbf{i}$, Fig. S3 $\uparrow$ ). In view of this and the limited catalyst concentration, the monometallic mechanisms could not be excluded in the $\mathbf{3}$ / $\mathrm{PEt}_{3}$ system. However, in the case of 2, the calculated energy barrier for the monometallic mechanism is too high (34.9 kcal $\mathrm{mol}^{-1}$ ) to be overcome under the experimental conditions. Therefore, only the bimetallic mechanism works in the 2 involved system. On the other hand, in the favorable bimetallic pathway, the overall energy barrier in the 3 catalyzed system is significantly lower than that in the 2 mediated reaction (10.9 vs. $20.2 \mathrm{kcal} \mathrm{mol}^{-1}$, Fig. 4 and 2). This is in line with the experimentally observed higher activity of 3 compared with 2 . $^{14 b}$

To gain deeper insights into this activity difference between 2 and $\mathbf{3}$ in the bimetal mediated chain propagations, the

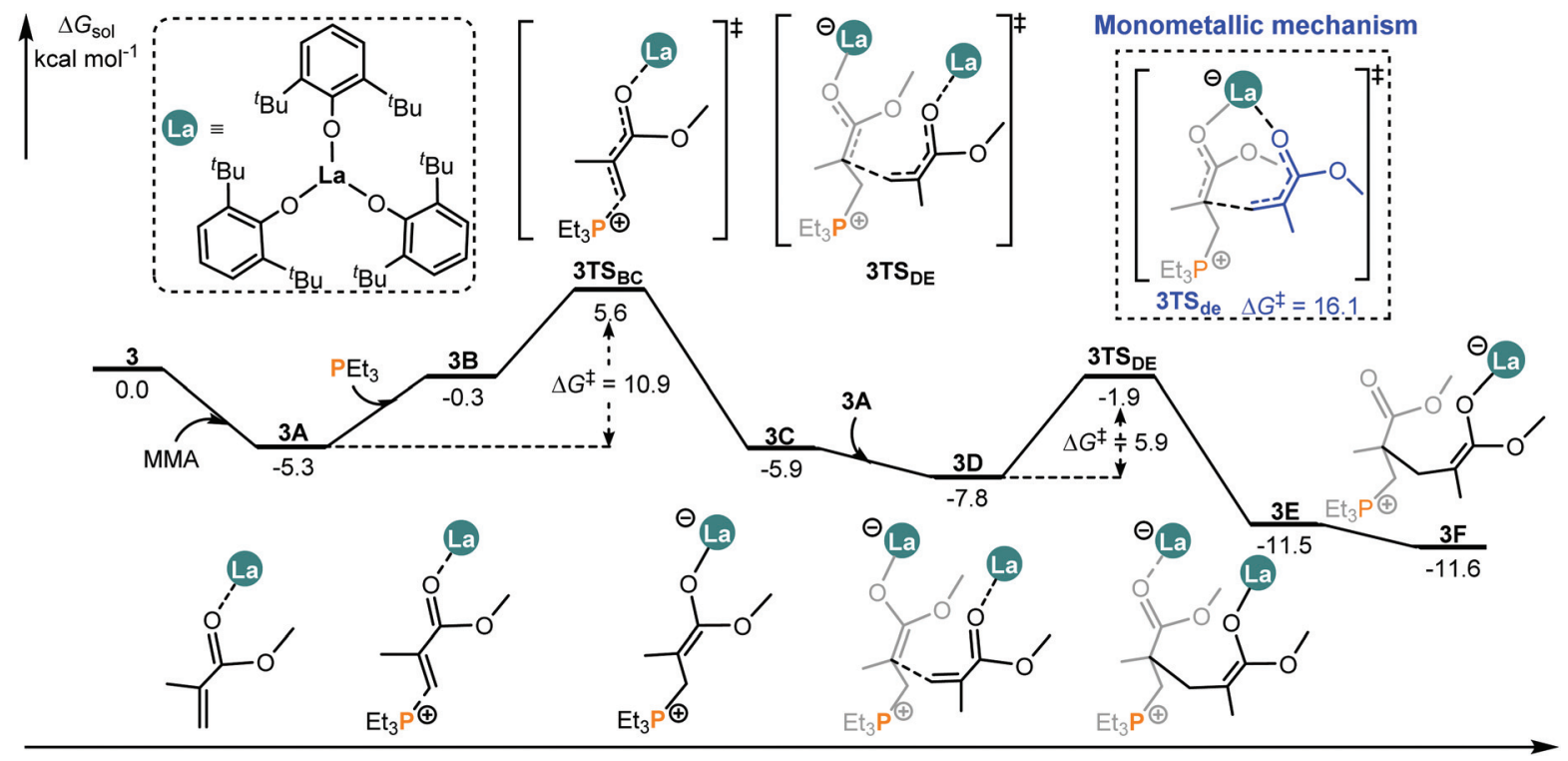

Fig. 4 Computed energy profiles for the 3/PEt 3 mediated (intermolecular RE/P systems) bimetallic pathway for MMA enchainment. Free energies $\left(\mathrm{kcal} \mathrm{mol}^{-1}\right)$ are relative to isolated reactants. 

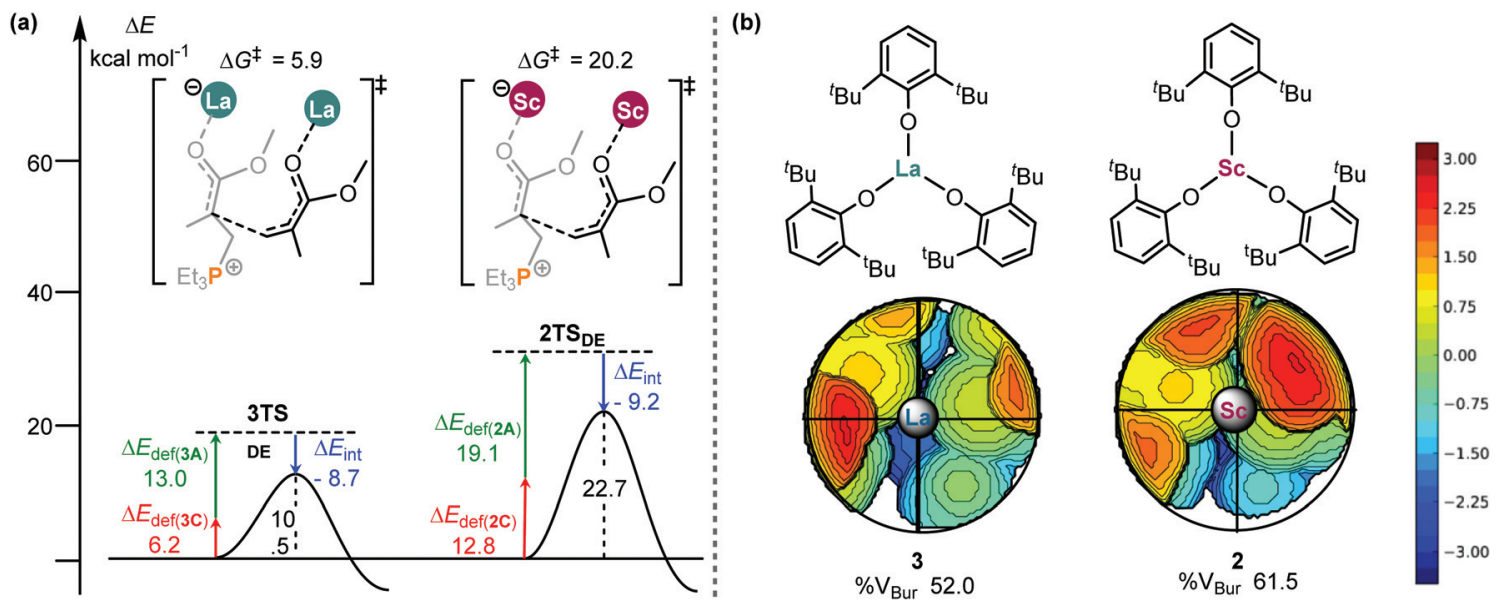

Fig. 5 (a) Distortion/interaction analyses $\left(\mathrm{kcal} \mathrm{mol}^{-1}\right)$ of $3 \mathrm{TS}_{\mathrm{DE}}$ and $2 \mathrm{TS}_{\mathrm{DE}}$; (b) topographical steric maps of catalysts 3 and 2.

similar distortion/interaction analyses ${ }^{21}$ of the two $\mathrm{C}-\mathrm{C}$ bond forming transition states (2TS $\mathrm{TSE}_{\mathrm{DE}}$ and $3 \mathrm{TS}_{\mathrm{DE}}$, Fig. 2 and 4$)$ were performed. As shown in Fig. 5, although the interaction between the two fragments in $3 \mathbf{T S}_{\mathrm{DE}}$ is weaker than that in $2 \operatorname{TS}_{\mathbf{D E}}\left(-8.7\right.$ vs. $\left.-9.2 \mathrm{kcal} \mathrm{mol}^{-1}\right)$, the total deformation energy of the former $\left(13.0+6.2=19.2 \mathrm{kcal} \mathrm{mol}^{-1}\right)$ is significantly smaller than that of the latter $\left(19.1+12.8=31.9 \mathrm{kcal} \mathrm{mol}^{-1}\right)$, which compensates for the less negative interaction energy in $3 \mathrm{TS}_{\mathrm{DE}}$, and eventually makes this TS more stable (free energy barrier of $5.9 v s .20 .2 \mathrm{kcal} \mathrm{mol}^{-1}$ ). These results suggest that the steric factor (geometrical deformation) accounts for the lower stability of $2 \mathbf{T S}_{\mathrm{DE}}$. In order to compare the sterics around the metal center in $\mathbf{2}$ and $\mathbf{3}$, the topographic steric maps were generated using the SambVca 2.0 web tool. ${ }^{22}$ When submitting an optimized structure on the web page of SambVca 2.0 and selecting the center site, the buried volume can be therefore calculated, simultaneously generating a topographic steric map. As expected, 3 had a lower percentage of buried volume in total (\% $V_{\text {Bur }}, 52.0 v s .61 .5$, Fig. 5 b) because of the larger radius of La; thus the relatively open enchainment environment in 3 could account for its higher activity. On the other hand, the torsion angle difference $\Delta \angle \mathrm{C} 1 \mathrm{C} 2 \mathrm{C} 3 \mathrm{P}=22.4^{\circ}$ and $\Delta \angle \mathrm{O} 5 \mathrm{C} 6 \mathrm{C} 5 \mathrm{C} 4=14.2^{\circ}$ in $2 \mathbf{T S}_{\mathbf{D E}}$ is significantly larger than those in $3 \mathbf{T S}_{\mathbf{D E}}$ $\left(\Delta \angle \mathrm{C} 1 \mathrm{C} 2 \mathrm{C} 3 \mathrm{P}=7.4^{\circ}\right.$ and $\Delta \angle \mathrm{O} 5 \mathrm{C} 6 \mathrm{C} 5 \mathrm{C} 4=2.1^{\circ}$, Fig. S4 $\left.\uparrow\right)$. Such a greater geometrical deformation in $\mathbf{2} \mathbf{T S}_{\mathbf{D E}}$ is also in line with the result of interaction/distortion analysis, resulting in a higher energy barrier and thus lower activity of the Sc complex.

\section{Lewis base effect on polymerization activity}

An experimental observation was noted that changing the substituents on the $\mathrm{P}$ atom in the Lewis base can also alter polymerization activities. ${ }^{14 b}$ For instance, the replacement of $\mathrm{PEt}_{3}$ with triphenylphosphine $\left(\mathrm{PPh}_{3}\right)$ noticeably decreased the activity. To understand the origin of such substituent effects, the energy profiles for MMA polymerization initiated by 2 and different bases $\mathrm{R}_{3} \mathrm{P}(\mathrm{R}=\mathrm{Cy}$ and $\mathrm{Ph})$ were calculated. Following the bimetallic mechanism, the effect of the Lewis base on the polymerization activity is mainly reflected in the chain initiation step; thus only the chain initiation process is considered here.

The computational results indicate that $\mathrm{PCy}_{3}$ as the Lewis base induced a lower energy barrier in comparison with $\mathrm{PPh}_{3}$ (Fig. 6). In addition, $\mathrm{PCy}_{3}$ involved zwitterionic species beyond

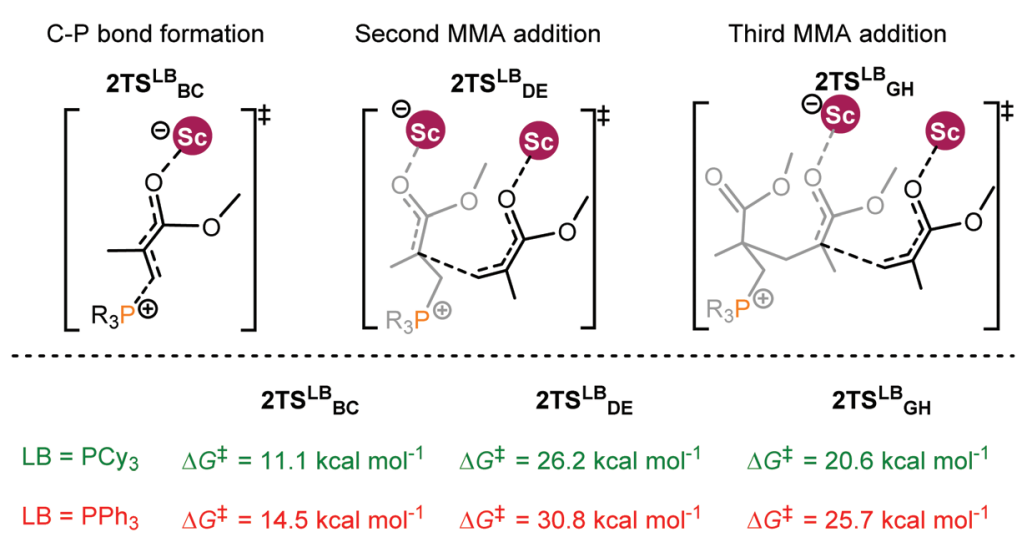

Fig. 6 Transition states for MMA polymerization initiated by the $2 / \mathrm{R}_{3} \mathrm{P}$ pair $(\mathrm{R}=\mathrm{Cy}$ and $\mathrm{Ph})$. Free energies $\left(\mathrm{kcal}^{\mathrm{mol}} \mathrm{m}^{-1}\right)$ are relative to isolated reactants. 
the $\mathrm{C}-\mathrm{P}$ bond formation transition state is more stable than the case of $\mathrm{PPh}_{3}\left(\mathrm{PCy}_{3}:-5.3 \mathrm{kcal} \mathrm{mol}{ }^{-1}\right.$ vs. $\mathrm{PPh}_{3}: 1.8 \mathrm{kcal}$ $\mathrm{mol}^{-1}$ ). This result is in agreement with the activity trend experimentally observed. However, it remains a challenge to provide a chemically meaningful explanation for the origin of such a discrepancy in the activity. To obtain a piece of information on such differences, similar distortion/interaction analyses were performed for the key transition states $\mathbf{T S} \mathbf{2}_{\mathbf{C y}}$ and TS2 ${ }_{\text {Ph }}$.

As shown in Fig. 7a, the two fragments (2C and $2 \mathrm{~A}$ ) are highlighted in black and green, respectively. The activation energy of each transition state $\left(\Delta E_{\mathrm{TS}}\right)$ is decomposed into the distortion energy $\left(\Delta E_{\mathrm{def}}\right)$ of the two reactive fragments and the interaction energy ( $\left.\Delta E_{\text {int }}\right)$ between the deformed two fragments. In $\mathbf{T S} 2_{\mathbf{P h}}$, the total distortion energy $\Delta E_{\text {def }}$ is $54.6 \mathrm{kcal}$ $\mathrm{mol}^{-1}$, which could be partially balanced out by its $\Delta E_{\text {int }}$ $\left(-6.9 \mathrm{kcal} \mathrm{mol}^{-1}\right)$ resulting in a $\Delta E_{\mathrm{TS}}$ of $47.7(54.6-6.9=47.7)$

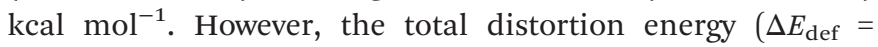
$55.9 \mathrm{kcal} \mathrm{mol}^{-1}$ ) in $\mathbf{T S} \mathbf{2}_{\mathbf{C y}}$ can be largely compensated by an interaction energy of $-9.2 \mathrm{kcal} \mathrm{mol}^{-1}$, thus giving a lower $\Delta E_{\mathrm{TS}}\left(46.7 \mathrm{kcal} \mathrm{mol}^{-1}\right)$. The distortion/interaction model analysis indicates that higher interaction energy could account for the stability of $\mathbf{T S} \mathbf{2}_{\mathbf{C y}}$ in comparison with $\mathbf{T S} \mathbf{2}_{\mathbf{P h}}$. To have a better understanding of such an interaction accounting for the relative stability of these two transition states, the ETS-NOCV ${ }^{23}$ (extended transition state and natural orbitals for chemical valence) calculations were performed by using the Amsterdam density functional (ADF) package ${ }^{24}$ to dissect the interaction energy (Fig. 7b). The interaction energy $\left(\Delta E_{\text {int }}^{\prime}\right.$ ) between the deformed $\mathbf{2 A}$ and $\mathbf{2} \mathbf{C}_{\mathbf{C y}}$ can be further dissected into Pauli repulsion $\left(\Delta E_{\text {Pauli }}\right)$, electrostatic interactions ( $\left.\Delta E_{\text {elstat }}\right)$, orbital interactions $\left(\Delta E_{\text {orbital }}\right)$, and dispersion interactions $\left(\Delta E_{\text {disp }}\right)$ (see computational methods in the ESI $\dagger$ for details). Of these interactions, the electrostatic ( $\Delta E_{\text {elstat }}$ ), orbital $\left(\Delta E_{\text {orbital }}\right)$, and dispersion $\left(\Delta E_{\text {disp }}\right)$ interactions are the stabilizing factors, while the Pauli repulsion $\left(\Delta E_{\text {Pauli }}\right)$ is the destabilizing factor. As shown in Fig. $7 \mathrm{~b}$, although the TS2 $\mathbf{C y}_{\mathbf{C}}$ is disfavored by Pauli repulsion compared with $\mathbf{2 T S}_{\mathbf{P h}}$ $\left(\Delta \Delta E_{\text {Pauli }}=112.3-98.9=+13.4 \mathrm{kcal} \mathrm{mol}^{-1}\right)$, it has stronger attractive orbital interactions $\left(\Delta \Delta E_{\text {orbital }}=-7.9 \mathrm{kcal} \mathrm{mol}^{-1}\right)$ and electrostatic interaction $\left(\Delta \Delta E_{\text {elstat }}=-7.3 \mathrm{kcal} \mathrm{mol}^{-1}\right)$ between the $\mathbf{2 A}$ and $\mathbf{2 C}$ moieties. These results indicate that the electronic properties of the Lewis base $\left(\mathrm{PPh}_{3}\right.$ and $\left.\mathrm{PCy}_{3}\right)$ can alter the electron-density of the $\mathrm{C}=\mathrm{C}$ bond in the $\mathbf{2 C}_{\mathbf{C y}}$ and $\mathbf{2 C}_{\mathbf{P h}}$, as also suggested by the CHelpG atomic charge ${ }^{25}$ (charges from the electrostatic potential using a grid-based method). As shown in Fig. 8a, the unsigned values of charge on $\mathbf{C} 1$ and $\mathbf{C} 3$ in $\mathbf{2} \mathbf{C}_{\mathbf{P h}}$ are smaller than those in $\mathbf{2} \mathbf{C}_{\mathbf{C y}}$, suggesting an inductive effect of the Ph groups in $\mathbf{2} \mathbf{C}_{\mathbf{P h}}$. This could account for the lower reactivity of $\mathrm{PPh}_{3}$ as a Lewis base because of the lower electron density on $\mathrm{C} 1$ atoms in comparison with $\mathrm{PCy}_{3}(-0.19$ vs. -0.45), rendering more electron flow during the 1,4-addition in the case of $\mathrm{PCy}_{3}$. On the other hand, to gain a deeper understanding of the orbital inter- a. Distorton/interaction model

$\Delta G^{\ddagger}=26.2 \mathrm{kcal} \mathrm{mol}^{-1}$

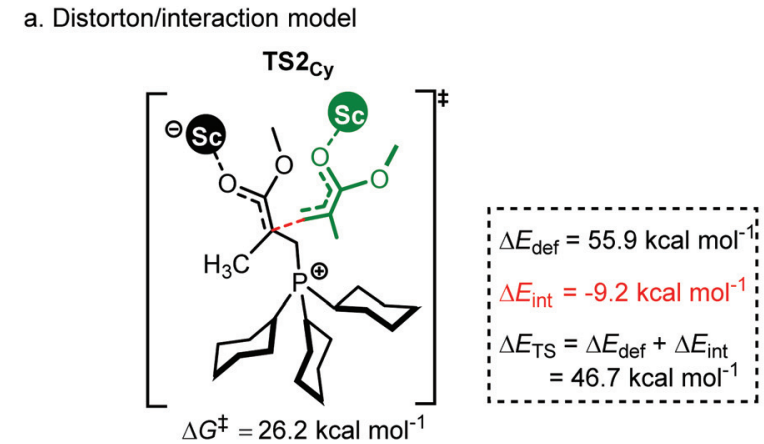
$=46.7 \mathrm{kcal} \mathrm{mol}^{-1}$

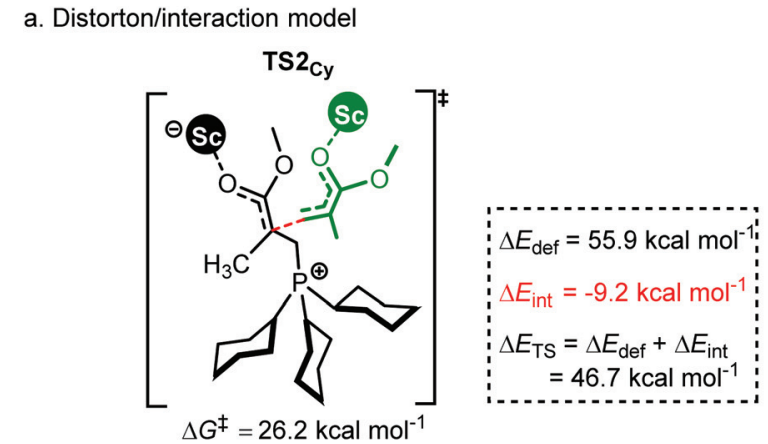

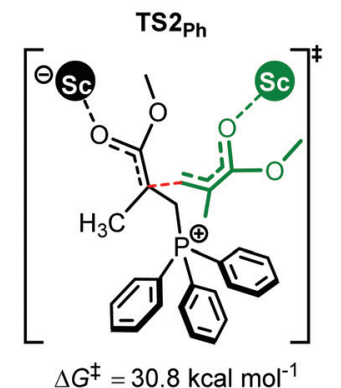

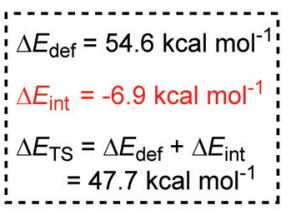

$\Delta G^{\ddagger}=30.8 \mathrm{kcal} \mathrm{mol}^{-1}$

b. Energy decomposition analysis (EDA) of the $2 \mathrm{~A}-2 \mathrm{C}_{\mathrm{Cy}_{\mathrm{y}}} / \mathbf{2 A}-\mathbf{2} \mathrm{C}_{\mathrm{Ph}}$ interaction energy ( $\Delta E_{\text {int }}^{\prime}$ )

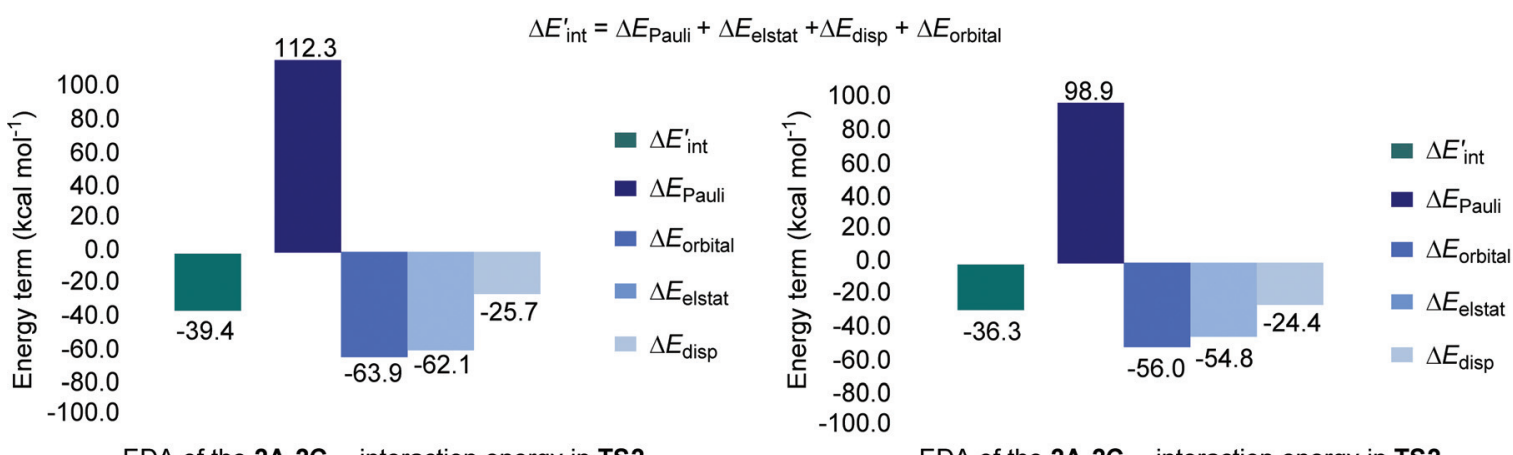

EDA of the $2 \mathrm{~A}-2 \mathrm{C}_{\mathrm{Cy}}$ interaction energy in $\mathrm{TS2}_{\mathrm{Cy}}$

EDA of the $2 \mathrm{~A}-\mathbf{2} \mathrm{C}_{\mathrm{Ph}}$ interaction energy in $\mathrm{TS} \mathbf{P}_{\mathrm{Ph}}$

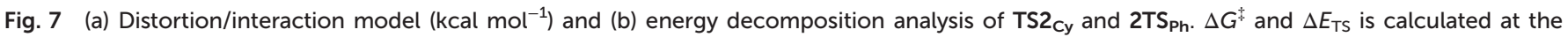

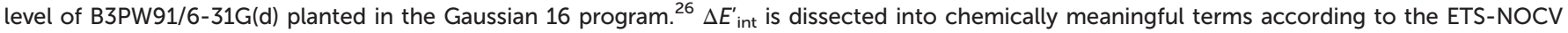
calculations at the level of B3LYP-D3/DZP planted in the Amsterdam density functional (ADF) package. ${ }^{24}$ 
(a) $\mathrm{CHelpG}$ atomic charges of $\mathbf{2 A}, 2 \mathrm{C}_{\mathrm{Cy}}, 2 \mathrm{C}_{\mathrm{Ph}}$ and $2 \mathrm{C}_{\mathrm{Ph}-\mathrm{OH}}$
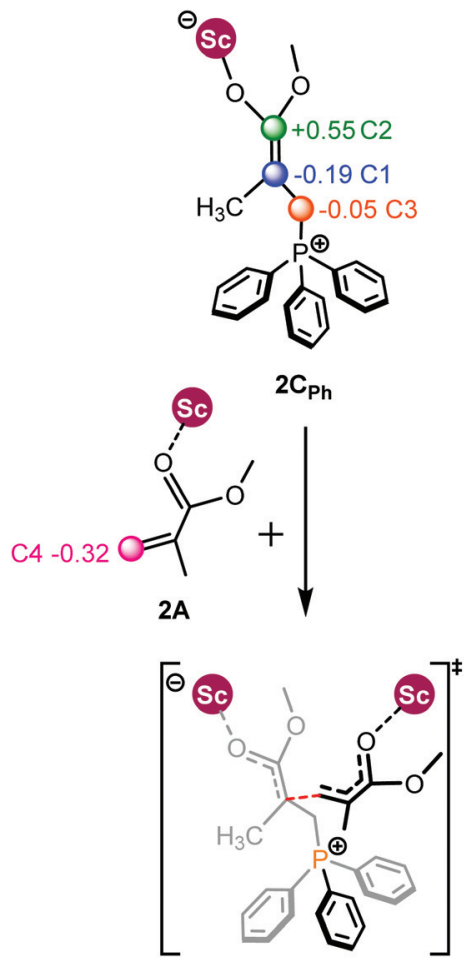

$\mathrm{TS}_{\mathrm{Ph}} \quad \Delta G^{\ddagger}=30.8 \mathrm{kcal} \mathrm{mol}^{-1}$
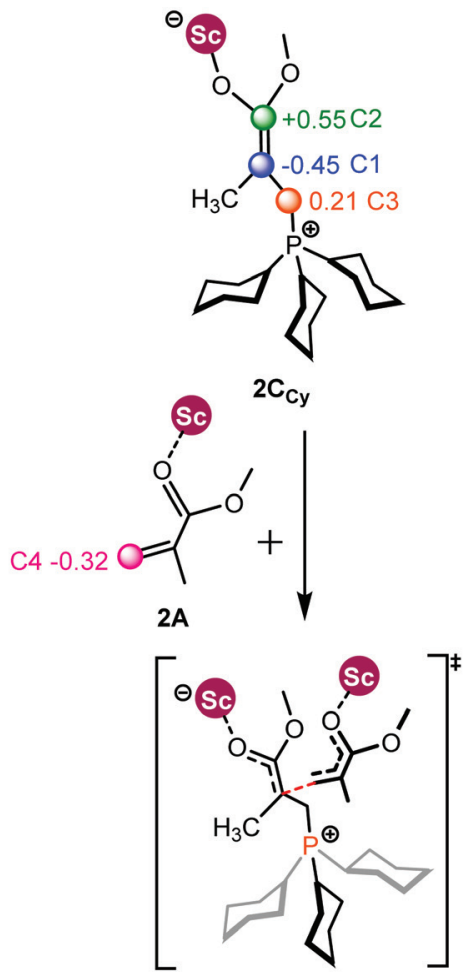

$\mathrm{TS2}_{\mathrm{Cy}} \Delta G^{\ddagger}=26.2 \mathrm{kcal} \mathrm{mol}^{-1}$
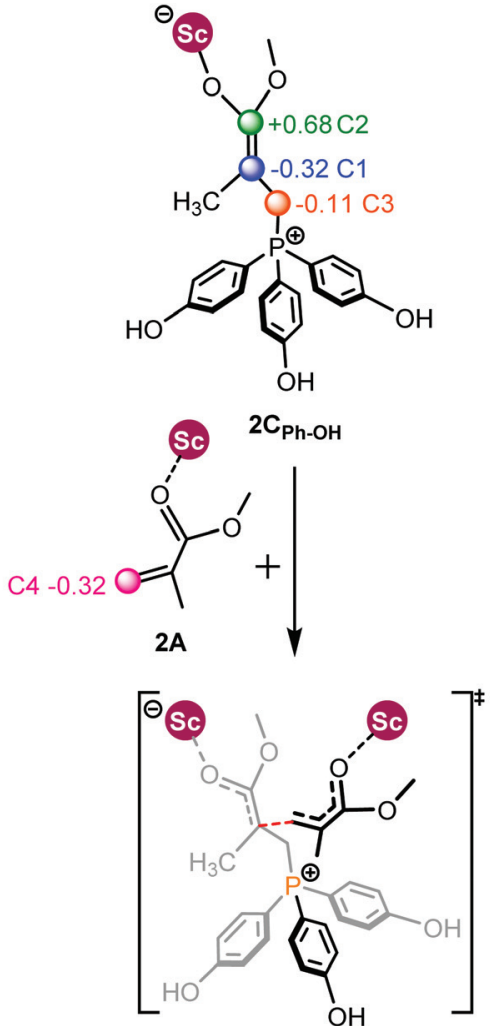

$\mathrm{TS} 2_{\mathrm{Ph}-\mathrm{OH}} \Delta \mathrm{G}^{\ddagger}=26.5 \mathrm{kcal} \mathrm{mol}^{-1}$

(b) Deformation densities and corresponding energies of $\mathrm{TS2}_{\mathrm{Cy}}$ and $\mathrm{TS} 2_{\mathrm{Ph}}$
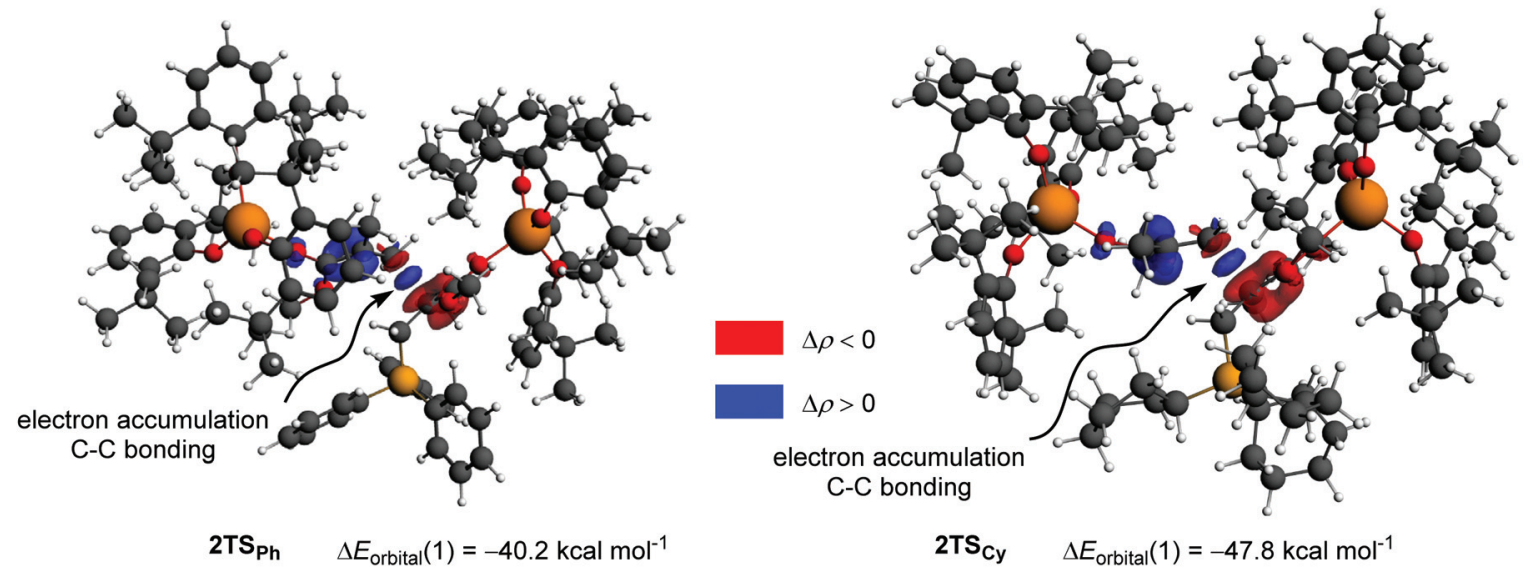

Fig. 8 (a) CHelpG atomic charge ${ }^{25}$ in $2 \mathrm{~A}, 2 \mathrm{C}_{\mathrm{Ph}}, 2 \mathrm{C}_{\mathrm{Cy}}$ and $2 \mathrm{C}_{\mathrm{Ph}-\mathrm{OH}}$; (b) leading deformation densities and corresponding energies for TS2 $\mathrm{Ph}$ and $2 \mathrm{TS}_{\mathrm{Cy}}$. The red color denotes charge depletion and the blue color represents charge accumulation $(|\Delta \rho|=0.004$ a.u. for all the density surfaces).

action, orbital analysis based on the NOCV approach was performed, which could give useful information about the reorganization of the electronic density in the transition states through the electronic deformation density. Fig. 8b shows the leading electronic deformation densities and the corresponding energies for $\mathbf{T S} \mathbf{2}_{\mathbf{C y}}$ and $\mathbf{2} \mathbf{T S} \mathbf{S}_{\mathbf{P h}}$. It is indicated that the $\Delta E_{\text {orbital }}$ energy of TS2 $\mathbf{C y}\left(-47.8 \mathrm{kcal} \mathrm{mol}^{-1}\right)$ is more negative than that of $2 \mathbf{T S}_{\mathbf{P h}}\left(-40.2 \mathrm{kcal} \mathrm{mol}{ }^{-1}\right)$. The charge flow from $\mathbf{2 C}_{\mathbf{C y}}$ (red region) to $\mathbf{2 A}$ (blue region) in $\mathbf{T S} \mathbf{2}_{\mathbf{C y}}$ is also more evident than that in $\mathbf{2 T S}_{\mathbf{P h}}$. Therefore, different Lewis bases could influence the electronic population in the intermediate such as 2C and further affect the stability of the addition reaction transition state. In order to further explore the regulation effect of the Lewis base, the hydroxyl (electron-donating group) substituted phenyls have been modelled (Fig. 8a). As expected, the calculated CHelpG charge on C1 changed from -0.19 to -0.32 and the addition reaction energy barrier reduced from 30.8 to $26.5 \mathrm{kcal} \mathrm{mol}^{-1}$. 
Table 1 Energy barrier for MMA addition mediated by original and modelled intramolecular Lewis pair RE/P catalysts ( 1 and $4-9$ ), respectively. Free energies are relative to isolated reactants

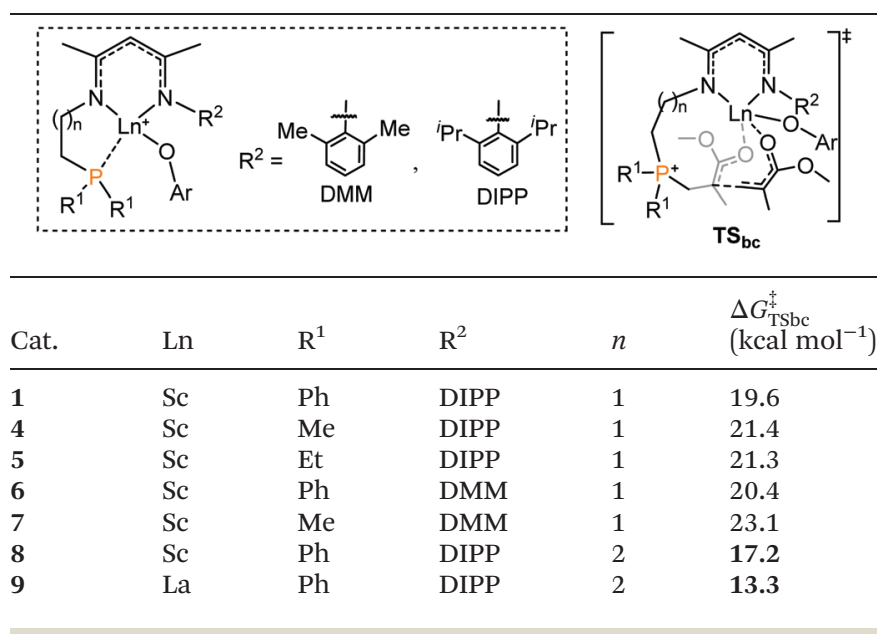

\section{Catalyst modification}

Inspired by the aforementioned calculation results, we speculated that it should be possible to improve the activity by modifying ligands in the intramolecular RE/P system. ${ }^{14 a}$ As aforementioned, the $\mathrm{P}-\mathrm{C}$ bond formation is not the rate determining step (Fig. 1), which was not considered here. As shown in Table 1, on the basis of original catalyst $\mathbf{1}$, appropriate substituent alteration has no significant effect on the MMA enchainment energy barrier $\left(\Delta G_{\mathrm{TSbc}}^{\ddagger}\right.$, cat. 1, 4-7). Interestingly, when the number of bridging methylenes increased to 2, the energy barrier decreased $\left(\Delta G_{1}^{\ddagger}=19.6\right.$ vs. $\left.\Delta G_{8}^{\ddagger}=17.2 \mathrm{kcal} \mathrm{mol}^{-1}\right)$. Besides, when the metal Sc is changed to La, the energy barrier obviously decreased by $6.3 \mathrm{kcal} \mathrm{mol}^{-1}\left(\Delta G_{1}^{\ddagger}=19.6 \mathrm{vs}\right.$. $\Delta G_{9}^{\ddagger}=13.3 \mathrm{kcal} \mathrm{mol}^{-1}$ ). These results suggest that the proper flexibility of the arm bridging intramolecular Lewis pair and larger-sized metal could be beneficial to the addition of MMA.

\section{Conclusions}

In summary, the origin of activity difference in the polymerization of methyl methacrylate (MMA) catalyzed by various rareearth/phosphorus Lewis pairs (RE/P), via Michael addition, has been computationally elucidated. The calculated energy landscapes indicate that the intramolecular $\mathrm{RE} / \mathrm{P}$ mediated MMA polymerization is a significant exergonic process and features a moderate energy barrier. In the case of intermolecular $\mathrm{RE} / \mathrm{P}$, the bimetallic mechanism is kinetically preferable over the monometallic pathway. Unlike the $\mathrm{Sc}(\mathrm{OAr})_{3} /$ $\mathrm{PEt}_{3}\left(\mathrm{Ar}=2,6-{ }^{t} \mathrm{Bu}_{2}-\mathrm{C}_{6} \mathrm{H}_{3}\right)$ Lewis pair, however, the La analogue may also follow a monometallic mechanism in view of limited catalyst concentration and surmountable enchainment energy barrier. The detailed structure and energy analyses disclosed that geometrical deformation required for achieving the enchainment transition state mainly accounts for the activity discrepancy of the rare-earth metal complex as a Lewis acid in the intermolecular RE/P system. Meanwhile, given the same Lewis acid, the observed activity difference of various $\mathrm{PR}_{3}$ Lewis bases ( $\mathrm{R}=\mathrm{Cy}$ and $\mathrm{Ph}$ ) could be ascribed to the electronic induction effect of the $\mathrm{R}$ group. Namely, the $\mathrm{R}$ group with stronger electron donation ability could increase the electron density on the reactive vinyl group and render more electron flow during the Michael addition, resulting in higher activity in comparison with the electron withdrawing group, which is in line with the experimentally observed activity trend. Besides, further computational modellings on a series of intramolecular $\mathrm{RE} / \mathrm{P}$ catalysts indicate that increasing the radius of the central metal or the flexibility of the bridge connecting Lewis pair in the catalyst is beneficial to improving catalytic activity. These theoretical results are expected to be useful for the design of a more efficient RE/P polymerization system.

\section{Conflicts of interest}

The authors declare no competing financial interest.

\section{Acknowledgements}

This work was partly supported by the NSFC (U1862115 and 21674014). The authors also thank the RICC (RIKEN Integrated Cluster of Clusters) and the Network and Information Center of the Dalian University of Technology for part of the computational resources. G. L. thanks the Innovation and Entrepreneurship Project of Overseas Returnees in Anhui Province (2020LCX006).

\section{References}

1 (a) F. Sugiyama, K. Satoh and M. Kamigaito, Regiospecific Radical Polymerization of Vinyl Methacrylate in the Presence of Lewis Acids into Soluble Polymers with Pendent Vinyl Ester Substituents, Macromolecules, 2008, 41, 3042-3048; (b) J. Ma, C. Cheng, G. Sun and K. L. Wooley, Well-Defined Polymers Bearing Pendent Alkene Functionalities via Selective RAFT Polymerization, Macromolecules, 2008, 41, 9080-9089.

2 (a) Y. Murali Mohan, V. Raghunadh, S. Sivaram and D. Baskaran, Reactive Polymers Bearing Styrene Pendants through Selective Anionic Polymerization of 4-Vinylbenzyl Methacrylate, Macromolecules, 2012, 45, 3387-3393; (b) S. Tanaka, R. Goseki, T. Ishizone and A. Hirao, Synthesis of Well-Defined Novel Reactive Block Polymers Containing a Poly(1,4-divinylbenzene) Segment by Living Anionic Polymerization, Macromolecules, 2014, 47, 23332339.

3 For reviewers, see: (a) C. Chen, Designing Catalysts for Olefin Polymerization and Copolymerization: Beyond Electronic and Steric Tuning, Nat. Rev. Chem., 2018, 2, 614; (b) M. Chen and C. Chen, Polar and Functionalized Polyolefins: New Catalysts, New Modulation Strategies and 
New Materials, Acta Polym. Sin., 2018, 11, 1372-1384; (c) D. J. Walsh, M. G. Hyatt, S. A. Miller and D. Guironnet, Recent Trends in Catalytic Polymerizations, ACS Catal., 2019, 9, 11153-11188; (d) A. Nakamura, S. Ito and K. Nozaki, Coordination-Insertion Copolymerization of Fundamental Polar Monomers, Chem. Rev., 2009, 109, 5215-5244; (e) B. Carrow and K. Nozaki, Transition-MetalCatalyzed Functional Polyolefin Synthesis: Effecting Control through Chelating Ancillary Ligand Design and Mechanistic Insights, Macromolecules, 2014, 47, 2541-2555; (f) L. Boffa and B. Novak, Copolymerization of Polar Monomers with Olefins Using Transition-Metal Complexes, Chem. Rev., 2000, 100, 1479-1493.

4 For recent reviews on the group-transfer polymerization, see: (a) E. Chen, Coordination Polymerization of Polar Vinyl Monomers by Single-Site Metal Catalysts, Chem. Rev., 2009, 109, 5157-5214; (b) B. Soller, S. Salzinger and B. Rieger, Rare Earth Metal-Mediated Precision Polymerization of Vinylphosphonates and Conjugated Nitrogen-Containing Vinyl Monomers, Chem. Rev., 2016, 116, 1993-2022.

5 (a) Y. Zhang, G. Miyake and E. Chen, Alane-Based Classical and Frustrated Lewis Pairs in Polymer Synthesis: Rapid Polymerization of MMA and Naturally Renewable Methylene Butyrolactones into High-Molecular-Weight Polymers, Angew. Chem., Int. Ed., 2010, 49, 10158-10162; (b) M. Hong, J. Chen and E. Chen, Polymerization of Polar Monomers Mediated by Main-Group Lewis Acid-Base Pairs, Chem. Rev., 2018, 118, 10551-10616; (c) W. Zhao, J. He and Y. Zhang, Lewis Pairs Polymerization of Polar Vinyl Monomers, Sci. Bull., 2019, 64, 1830-1840; (d) Y. Jia, Y. Wang, W. Ren, T. Xu, J. Wang and X. Lu, Mechanistic Aspects of Initiation and Deactivation in N-Heterocyclic Olefin Mediated Polymerization of Acrylates with Alane as Activator, Macromolecules, 2014, 47, 1966-1972; (e) H. Wang, Q. Wang, J. He and Y. Zhang, Living Polymerization of Acrylamides Catalysed by N-heterocyclic Olefin-based Lewis Pairs, Polym. Chem., 2019, 10, 35973603; $(f)$ Y. Bai, J. He and Y. Zhang, Ultra-High-MolecularWeight Polymers Produced by the Immortal PhosphineBased Catalyst System, Angew. Chem., Int. Ed., 2018, 57, 17230-17234; (g) Y. Bai, H. Wang, J. He and Y. Zhang, Rapid and Scalable Access to Sequence-Controlled DHDM Multiblock Copolymers by FLP Polymerization, Angew. Chem., Int. Ed., 2020, 59, 11613-11619; (h) M. McGraw, R. Clarke and E. Chen, Compounded Sequence Control in Polymerization of One-Pot Mixtures of Highly Reactive Acrylates by Differentiating Lewis Pairs, J. Am. Chem. Soc., 2020, 142, 5969-5973.

6 (a) Q. Wang, W. Zhao, S. Zhang, J. He, Y. Zhang and E. Chen, Living Polymerization of Conjugated Polar Alkenes Catalyzed by N-Heterocyclic Olefin-Based Frustrated Lewis Pairs, ACS Catal., 2018, 8, 3571-3578; (b) T. Xu and E. Chen, Probing Site Cooperativity of Frustrated Phosphine/Borane Lewis Pairs by a Polymerization Study, J. Am. Chem. Soc., 2014, 136, 1774-
1777; (c) M. Knaus, M. Giuman, A. Pöthig and B. Rieger, End of Frustration: Catalytic Precision Polymerization with Highly Interacting Lewis Pairs, J. Am. Chem. Soc., 2016, 138, 7776-7781.

7 (a) X. Wang, Y. Zhang and M. Hong, Controlled and Efficient Polymerization of Conjugated Polar Alkenes by Lewis Pairs Based on Sterically Hindered Aryloxide Substituted Alkylaluminum, Molecules, 2018, 23, 442-453; (b) X. Wang and M. Hong, Precise Control of Molecular Weight and Stereospecificity in Lewis Pair Polymerization of Semifluorinated Methacrylates: Mechanistic Studies and Stereocomplex Formation, Macromolecules, 2020, 53, 46594669.

8 (a) W. Zhao, Q. Wang, J. He and Y. Zhang, Chemoselective and living/controlled polymerization of polar divinyl monomers by N-heterocyclic olefin based classical and frustrated Lewis pairs, Polym. Chem., 2019, 10, 4328-4335; (b) Y. Bai and Y. Zhang, Polymerization of Polar Vinyl Monomers Catalyzed by Lewis Pairs, Acta Polym. Sin., 2019, 50, 233246.

9 (a) E. Chen and M. Cooney, Amphicatalytic Polymerization: Synthesis of Stereomultiblock Poly(methyl methacrylate) with Diastereospecific Ion Pairs, J. Am. Chem. Soc., 2003, 125, 7150-7151; (b) Y. Ning and E. Chen, Diastereospecific Ion-Pairing Polymerization of Functionalized Alkenes by Metallocene/Lewis Acid Hybrid Catalysts, Macromolecules, 2006, 39, 7204-7215.

10 (a) H. Ji, B. Wang, L. Pan and Y. Li, Lewis Pairs for RingOpening Alternating Copolymerization of Cyclic Anhydrides and Epoxides, Green Chem., 2018, 20, 641-648; (b) X. Li, B. Wang, H. Jia and Y. Li, Insights into the Mechanism for Ring-Opening Polymerization of Lactide Catalyzed by $\mathrm{Zn}\left(\mathrm{C}_{6} \mathrm{~F}_{5}\right)_{2} /$ Organic Superbase Lewis Pairs, Catal. Sci. Technol., 2016, 6, 7763-7772.

11 A. Londaitsbehere, M. Sudupe, M. Mosquera, T. Cuenca and J. Cano, MMA Polymerization with Group 4 Alkyl-Free 14-Electron d ${ }^{0}$ Species, Eur. J. Inorg. Chem., 2020, 2020, 1589-1595.

12 (a) W. Mao, L. Xiang, C. Lamsfus, L. Maron, X. Leng and Y. Chen, Are Sc-C and Sc-P Bonds Reactive in Scandium Phosphinoalkylidene Complex? Insights on a Versatile Reactivity, Chin. J. Chem., 2018, 36, 904-908; (b) C. Xue, Y. Luo, H. Teng, Y. Ma, M. Nishiura and Z. Hou, OrthoSelective $\mathrm{C}-\mathrm{H}$ Borylation of Aromatic Ethers with Pinacolborane by Organo Rare-Earth Catalysts, ACS Catal., 2018, 8, 5017-5022; (c) Y. Luo, H. Teng, C. Xue, M. Nishiura and Z. Hou, Yttrium-Catalyzed Regioselective $\alpha-\mathrm{C}-\mathrm{H}$ Silylation of Methyl Sulfides with Hydrosilanes, ACS Catal., 2018, 8, 8027-8032.

13 (a) M. Nishiura and Z. Hou, Novel Polymerization Catalysts and Hydride Clusters from Rare-earth Metal Dialkyls, Nat. Chem., 2010, 2, 257-268; (b) M. Nishiura, F. Guo and Z. Hou, Half-Sandwich Rare-Earth-Catalyzed Olefin Polymerization, Carbometalation, and Hydroarylation, Acc. Chem. Res., 2015, 48, 2209-2220; (c) D. Cui, Studies on Homo- and Co-polymerizations of Polar and Non-polar 
Monomers Using Rare-earth Metal Catalysts, Acta Polym. Sin., 2020, 51, 12-29; (d) C. Wang, G. Luo, M. Nishiura, G. Song, A. Yamamoto, Y. Luo and Z. Hou, HeteroatomAssisted Olefin Polymerization by Rare-earth Metal Catalysts, Sci. Adv., 2017, 3, e1701011.

14 (a) P. Xu, Y. Yao and X. Xu, Frustrated Lewis Pairs Like Reactivity of Rare-Earth Metal Complexes: 1,4-Addition Reactions and Polymerizations of Conjugated Polar Alkenes, Chem. - Eur. J., 2017, 23, 1263-1267; (b) P. Xu and $\mathrm{X}$. Xu, Homoleptic Rare-Earth Aryloxide Based Lewis Pairs for Polymerization of Conjugated Polar Alkenes, ACS Catal., 2018, 8, 198-202; (c) P. Xu, L. Wu, L. Dong and X. Xu, Chemoselective Polymerization of Polar Divinyl Monomers with Rare-Earth/Phosphine Lewis Pairs, Molecules, 2018, 23, 360 .

15 Y. Zhang, G. Miyake, M. John, L. Falivene, L. Caporaso, L. Cavallo and E. Chen, Lewis Pair Polymerization by Classical and Frustrated Lewis Pairs: Acid, Base and Monomer Scope and Polymerization Mechanism, Dalton Trans., 2012, 41, 9119-9134.

16 J. He, Y. Zhang, L. Falivene, L. Caporaso, L. Cavallo and E. Chen, Chain Propagation and Termination Mechanisms for Polymerization of Conjugated Polar Alkenes by [Al]Based Frustrated Lewis Pairs, Macromolecules, 2014, 47, 7765-7774.

17 W. Ottou, E. Conde-Mendizabal, A. Pascual, A. Wirotius, D. Bourichon, J. Vignolle, F. Robert, Y. Landais, J. Sotiropoulos, K. Miqueu and D. Taton, Organic Lewis Pairs Based on Phosphine and Electrophilic Silane for the Direct and Controlled Polymerization of Methyl Methacrylate: Experimental and Theoretical Investigations, Macromolecules, 2017, 50, 762-774.

18 Y. Jia, W. Ren, S. Liu, T. Xu, Y. Wang and X. Lu, Controlled Divinyl Monomer Polymerization Mediated by Lewis Pairs: A Powerful Synthetic Strategy for Functional Polymers, ACS Macro Lett., 2014, 3, 896-899.

19 (a) Y. Luo, Y. Luo, J. Qu and Z. Hou, QM/MM Studies on Scandium-Catalyzed Syndiospecific Copolymerization of Styrene and Ethylene, Organometallics, 2011, 30, 29082919; (b) Y. Zhao, G. Luo, X. Kang, F. Guo, X. Zhu,

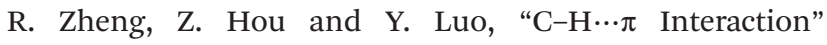
Regulates the Stereoselectivity in Olefin Polymerization, Chem. Commun., 2019, 55, 6689-6692; (c) X. Kang, Y. Song, Y. Luo, G. Li and Z. Hou, Computational Studies on Isospecific Polymerization of 1-Hexene Catalyzed by Cationic Rare Earth Metal Alkyl Complex Bearing a $C_{3}{ }^{i} \mathrm{Pr}-$ trisox Ligand, Macromolecules, 2012, 45, 640-651; (d) X. Kang, Y. Luo and Z. Hou, Theoretical Insights into Olefin Polymerization Catalyzed by Cationic Organo RareEarth Metal Complexes, in Computational Quantum Chemistry: Insights into Polymerization Reactions, ed. M. Soroush, Elsevier, Amsterdam, The Netherlands, 2019, pp. 327-356.

20 R. G. Pearson, Proc. Nati. Acad. Sci. US, 1986, 83, 8440-8441.

21 (a) F. Bickelhaupt and K. Houk, Analyzing Reaction Rates with the Distortion/Interaction-Activation Strain Model,
Angew. Chem., Int. Ed., 2017, 56, 10070-10086; (b) I. Fernández and F. Bickelhaupt, Bioorthogonal Cycloadditions: Computational Analysis with the Distortion/Interaction Model and Predictions of Reactivities, Chem. Soc. Rev., 2014, 43, 4953-4967; (c) F. Liu, Y. Liang and K. Houk, Bioorthogonal Cycloadditions: Computational Analysis with the Distortion/Interaction Model and Predictions of Reactivities, Acc. Chem. Res., 2017, 50, 2297-2308; (d) K. Kitaura and K. Morokuma, A New Energy Decomposition Scheme for Molecular Interactions within the Hartree-Fock Approximation, Int. J. Quantum Chem., 1976, 10, 325-340.

22 (a) A. Poater, B. Cosenza, A. Correa, S. Giudice, F. Ragone, V. Scarano and L. Cavallo, SambVca: A Web Application for the Calculation of the Buried Volume of N-Heterocyclic Carbene Ligands, Eur. J. Inorg. Chem., 2009, 2009, 17591766; (b) L. Falivene, R. Credendino, A. Poater, A. Petta, L. Serra, R. Oliva, V. Scarano and L. Cavallo, SambVca 2. A Web Tool for Analyzing Catalytic Pockets with Topographic Steric Maps, Organometallics, 2016, 35, 2286-2293. See also https://www.molnac.unisa.it/OMtools/sambvca2.0/.

23 M. Mitoraj, A. Michalak and T. Ziegler, A Combined Charge and Energy Decomposition Scheme for Bond Analysis, J. Chem. Theory Comput., 2009, 5, 962-975.

24 (a) G. te Velde, F. Bickelhaupt, E. Baerends, C. Fonseca Guerra, S. van Gisbergen, J. Snijders and T. Ziegler, Chemistry with ADF, J. Comput. Chem., 2001, 22, 931-967; (b) E. Baerends, J. Autschbach, D. Bashford, A. Bérces, F. Bickelhaupt, C. Bo, P. Boerrigter, L. Cavallo, D. Chong, L. Deng, R. Dickson, D. Ellis, M. van Faassen, L. Fan, T. Fischer, C. Fonseca Guerra, A. Ghysels, A. Giammona, S. van Gisbergen, A. Götz, J. Groeneveld, O. Gritsenko, M. Grüning, F. Harris, P. van den Hoek, C. Jacob, H. Jacobsen, L. Jensen, G. van Kessel, F. Kootstra, M. Krykunov, E. van Lenthe, D. McCormack, A. Michalak, M. Mitoraj, J. Neugebauer, V. Nicu, L. Noodleman, V. Osinga, S. Patchkovskii, P. Philipsen, D. Post, C. Pye, W. Ravenek, J. Rodríguez, P. Ros, P. Schipper, G. Schreckenbach, M. Seth, J. Snijders, M. Solà, M. Swart, D. Swerhone, G. te Velde, P. Vernooijs, L. Versluis, L. Visscher, O. Visser, F. Wang, T. Wesolowski, E. van Wezenbeek, G. Wiesenekker, S. Wolff, T. Woo, A. Yakovlev and T. Ziegler, ADF2009.01, Theoretical Chemistry, Vrije Universiteit, Amsterdam.

25 C. Breneman and K. Wiberg, Determining Atom-Centered Monopoles from Molecular Electrostatic Potentials. The Need for High Sampling Density in Formamide Conformational Analysis, J. Comput. Chem., 1990, 11, 361373.

26 M. J. Frisch, G. W. Trucks, H. B. Schlegel, G. E. Scuseria, M. A. Robb, J. R. Cheeseman, G. Scalmani, V. Barone, G. A. Petersson, H. Nakatsuji, X. Li, M. Caricato, A. V. Marenich, J. Bloino, B. G. Janesko, R. Gomperts, B. Mennucci, H. P. Hratchian, J. V. Ortiz, A. F. Izmaylov, J. L. Sonnenberg, D. Williams-Young, F. Ding, F. Lipparini, F. Egidi, J. Goings, B. Peng, A. Petrone, T. Henderson, 
D. Ranasinghe, V. G. Zakrzewski, J. Gao, N. Rega, G. Zheng, W. Liang, M. Hada, M. Ehara, K. Toyota, R. Fukuda, J. Hasegawa, M. Ishida, T. Nakajima, Y. Honda, O. Kitao, H. Nakai, T. Vreven, K. Throssell, J. A. Montgomery Jr., J. E. Peralta, F. Ogliaro, M. J. Bearpark, J. J. Heyd, E. N. Brothers, K. N. Kudin, V. N. Staroverov, T. A. Keith,
R. Kobayashi, J. Normand, K. Raghavachari, A. P. Rendell, J. C. Burant, S. S. Iyengar, J. Tomasi, M. Cossi, J. M. Millam, M. Klene, C. Adamo, R. Cammi, J. W. Ochterski, R. L. Martin, K. Morokuma, O. Farkas, J. B. Foresman and D. J. Fox, Gaussian 16, Revision A.03, Gaussian, Inc., Wallingford, CT, 2016. 